\title{
Spending more to save ... .
}

\section{London}

SAvE British Science (SBS), the pressure group, this week demanded an increase of $£ 1,300$ million in government support for research and development, as well as far-reaching changes in British science education. In a document headed "Benchmarks for 2000", SBS also asks for 50 per cent increase in the numbers of science and engineering graduates, stipends for graduate students comparable with those obtainable at the beginning of "alternative careers" and a full-time Minister of Science and Technology.

SBS's argument is mostly based on comparisons between Britain and countries elsewhere, notably those of the European Communities (EC) and of the Organization for Economic Cooperation and Development (OECD). It says that the year 2000 has been chosen as a date by which its reforms could reasonably be implemented.

On education, SBS asks that all secondary-school students should be taught science by qualified teachers, and that secondary students should be encouraged to stay at school, with the intention that 80 per cent of those aged 16 to 18 should be in fulltime education.

Similarly, SBS asks that more than half of young people should be engaged in some form of higher education, not necessarily in traditional degree courses. The proportion of young people undertaking technical training should be increased by a factor of at least two or three, according to the document. It draws attention to the declining proportion of university teachers younger than 35 , noting that recruitment for the future should begin now.

SBS also wants to see a 50 per cent increase in the numbers of graduate students who, it says, should be paid salaries appropriate to people beginning work as lawyers and accountants.

The case for increased support for civil research turns on comparisons with performance elsewhere, notably in Germany, Japan and the United States. Thus SBS wants spending on civil research and development to increase to $2.3 \mathrm{per}$ cent of gross domestic product (GDP) by 1995 , and to 2.7 per cent by the end of the decade.

The government's share of this (estimated to have fallen from 0.72 per cent in 1981 to 0.55 per cent now) would have to increase to 0.8 per cent in 1995 , whence the $£ 1,300$ million a year. SBS also endorses the claims of universities and polytechnics for an injection of $£ 1,000$ million to replace obsolete equipment and buildings, and argues that restoring the capacity of the grant-making system requires an extra $£ 400$ million.
SBS says that industrial spending on civil research will have almost to double in numerical terms, implying by the end of the decade extra spending of $£ 3,700$ million a year on civil research and development funded by industry's own resources. It would be for the government to devise the appropriate incentives, SBS says.

That would be one task of the proposed Minister for Science and Technology. SBS says that it does not seek to be "overprescriptive" at this stage about that person's role, but that such an appointment would be a "signal . . . that science policy is going to be taken seriously for the first time in Britain.

John Maddox

HIGH-ENERGY PHYSICS

\section{HERA completed}

\section{Munich}

Hera, the first electron-proton collider in the world, was completed at DESY (Deutsches Elektronen Synchrotron) in Hamburg earlier this month and is now being readied for start-up next year. The 6,336-metre-long oval tunnel is located 20 metres beneath the Bahrenfeld section of Hamburg.

The first particle beams at full energy are expected in the spring of 1991 and the first collisions in the summer. Protons will circulate at $820 \mathrm{GeV}$, electrons at $30 \mathrm{GeV}$, and collisions will be monitored by two large detectors known as ZEUS and H1.

HERA (Hadron Elektron Ring Anlage), which took six and a half years to build and cost approximately DM1,000 million (about $\$ 675$ million at current exchange rates), is the first European accelerator to use superconducting magnets.

The German Research Minister, Heinz Riesenhuber, last week ceremonially pushed a button to start the process of cooling the particles in the storage rings. Riesenhuber said that he was proud that HERA had been completed on time and within its budget.

HERA is expected to explore the structure of the nucleon in greater depth than ever before, and to investigate the weak force. Although current theoretical estimates indicate that the elusive top quark is a little too massive to be detected at HERA, researchers there hope that HERA's high resolution may allow them to determine if quarks are really the smallest constituents of matter.

Many countries contributed to HERA, both scientifically and financially, including France, Israel, Italy, Canada and the Netherlands. More than 700 researchers are working in high-energy physics and another 250 in synchrotron science at the facility.

\section{Database for plant species}

\section{London}

BOTANISTs are compiling a computer database of plant species names despite the chronic shortage of funds for taxonomic research. A meeting held on 12-13 November at the Royal Botanic Gardens, Kew, attracted delegates from 45 institutions to discuss Kew's own database initiative, the Species Plantarum Project (SPP). Grenville Lucas, keeper of the Herbarium at Kew, thinks that the SPP will cost some $\$ 10-20$ million, but the need for a taxonomic database is so great that botanists simply cannot wait for funds. "If we don't start now", Lucas says, "it'll never get done."

The first five-year phase of SPP will be a simple checklist of all 250,000 species of seed-plant, ferns and mosses. The second phase will be an in-depth treatment of basic plant taxonomy and biogeography, a taxonomic equivalent of the Human Genome Project. When complete, the SPP should supplant its eighteenthcentury forebear, Linnaeus's Species Plantarum. SPP is just one of several ideas designed to cater for an increasing need for up-to-date taxonomic information. A meeting convened in Delphi, Greece last month (11-16 October) to discuss designs for a Global Plant Species Information System (GPSIS) was "hijacked", says Frank Bisby of the University of Southampton, by researchers who wanted immediate action. The result was the formation of the GPSIS Action Group, which is committed to producing a species checklist in just three years that might include fungi and algae as well as vascular plants and mosses.

Some of the work has already been done by researchers working on particular plant groups. Bisby's laboratory, for instance, is working on a checklist of the 16,500 species of legumes (one-twelfth of all species of flowering plant) as a part of the International Legume Database and Information Service (ILDIS). Bisby views the ILDIS checklist as a good working model of the GPSIS initiative, but is angry about the dearth of secure funding for taxonomy: seen, he says, as of "marginal interest to many people, but a lot of interest to nobody".

Bisby thinks that the SPP and the GPSIS Action Group will join forces, given that their aims are virtually identical. But once a database is up and running, funds will be needed to maintain and update it. "The management of it is going to be a monster" concedes Lucas, who is nevertheless confident of success with "the fraternity of taxonomy worldwide shoving behind the wheel". 